\title{
Potential Complications and Sequelae of SARS-CoV-2 Infection
}

\author{
Jyoti Nath Modi, Amrita Ghosh', Ranabir Pal2 ${ }^{2}$, Rajashekar Mohan ${ }^{3}$, Luis Rafael Moscote-Salazar, Santosh Wakode ${ }^{5}$, Amit Agrawal ${ }^{6}$ \\ Departments of OBG, ${ }^{5}$ Physiology and ${ }^{6}$ Neurosurgery, All India Institute of Medical Sciences, Bhopal, Madhya Pradesh, ${ }^{1}$ Department of Biochemistry, Calcutta Medical \\ College, Kolkata, West Bengal, ${ }^{2}$ Department of Community Medicine, MGM Medical College and Hospital, Kishanganj, Bihar, ${ }^{3}$ Department of Surgery, K S Hegde \\ Medical Academy of Nitte (Deemed to be University), Mangalore, Karnataka, India, ${ }^{4}$ Department of Neurosurgery, University of Cartagena, Cartagena de Indias, \\ Colombia
}

\section{Abstract}

COVID-19 disease caused by the SARS-CoV-2 virus affects almost all the organ systems of the body leading to multisystemic morbidities and typical complications hitherto unheard of in seasonal "flu" or SARS-CoV-1 epidemic. Acute life-threatening complications range from unabated pneumonia and respiratory failure to "cytokine release syndrome" or "cytokine storm," cardiovascular and cerebrovascular morbidities leading to multiorgan failure, followed by death. The prepathogenesis, pathogenesis, and the clinico-demographic characteristics of SARS-CoV-2 infection have shown a wide variation across different populations, geographical regions, race, and ethnicities. While there are some commonalities, there continues to be a lack of consensus on several aspects of this infection such as its natural history, infectivity, transmission, and its mutagenic strains. Further, newer aspects of the disease have continued to emerge with passing time since its first appearance in December 2019 in Wuhan, China. The initial case descriptions varied from asymptomatic to mild illness requiring minimal monitoring and support to severe COVID-19 disease requiring admission to intensive care facilities and a higher morbidity and mortality. Only subsequently it was recognized that even after the clinical recovery from illness, the infection may persist for a longer time, with continuing damage to some organ systems and sequelae that compromise the quality of life. These have been called the long-term complications or "chronic COVID" infection, and they may be noted even months after recovery from the acute form of disease. While thus far the global efforts have been rightfully directed at combating the acute illness in the pandemic and maximizing recovery, it is possible that we may soon be faced with the challenge of a "secondary pandemic" with a significant burden of chronic COVID and sequelae. This will be a strain on the palliative care, rehabilitative care, and domiciliary care network essentially supported by the primary health-care providers or first-contact physicians worldwide. This approach is in alignment with an emphasis that the WHO placed on the third clinical outcome indicator "functioning" in addition to the two indicators "cure" and "death." The present review discusses the pathophysiology, clinical aspects, and implications of long-term effects of SARS-CoV-2 infection. It is expected to help in sensitizing the health-care workers and policymakers for preparing adequately and timely for dealing with these effects.

Keywords: Cardiopulmonary, chronic COVID, COVID-19, glucometabolic, long-term complications, neuropsychiatric, SARS-CoV-2

\section{INTRODUCTION}

COVID-19 disease caused by the SARS-CoV-2 virus (also called the novel coronavirus) has presented as an exceptional and unmitigated emergency impacting global health-care delivery system in high- as well as low- and middle-income countries. Since the first reported case in December 2019, ${ }^{[1]}$ thesevere acute respiratory syndrome caused by this novel virus $^{[2]}$ has taken the form of one of the largest outbreaks of this century. ${ }^{[3-5]}$ The World Health Organization declared COVID-19 disease a pandemic on January 17, 2020. The spectrum of clinical presentation of the COVID-19 disease is quite varied in terms of severity and organ system involvement. The clinical and demographic characteristics of the disease

\begin{tabular}{|l|l|}
\hline \multicolumn{3}{|c|}{ Access this article online } \\
\hline Quick Response Code: & Website: \\
& www.ijrc.in \\
\cline { 2 - 2 } & \\
&
\end{tabular}

are also at variance in different populations, geographical regions, races, and ethnicities. Presence of comorbidities such as diabetes, hypertension (HTN), obesity, and advanced age are some of the conditions that predispose to a more severe form of disease and a higher mortality. Initial studies have reported largely on the acute form of disease, symptoms, and clinical outcomes, particularly in hospitalized patients, as well

Address for correspondence: Prof. Amit Agrawal, Department of Neurosurgery, All India Institute of Medical Sciences, Saket Nagar, Bhopal - 462 020, Madhya Pradesh, India. E-mail: dramitagrawal@gmail.com

This is an open access journal, and articles are distributed under the terms of the Creative Commons Attribution-NonCommercial-ShareAlike 4.0 License, which allows others to remix, tweak, and build upon the work non-commercially, as long as appropriate credit is given and the new creations are licensed under the identical terms.

For reprints contact:WKHLRPMedknow_reprints@wolterskluwer.com

How to cite this article: Modi JN, Ghosh A, Pal R, Mohan R, Moscote-Salazar LR, Wakode S, et al. Potential complications and sequelae of SARS-CoV-2 infection. Indian J Respir Care 2021;10:4-9.

Received: $18-09-2020 \quad$ Revised: $25-11-2020$ Accepted: 05-12-2020 Published: 31-01-2021 
as on severe COVID-19 disease leading to multiorgan damage and failure. ${ }^{[6-9]}$ Subsequently, some studies have reported that coronavirus infection can result in residual damage to the organs and long-term morbidity with resultant secondary disability. ${ }^{[10,11]}$ Such kind of damage to the organ systems has also been termed "chronic COVID," and has been reported as long-term cardiopulmonary, endocrine, glucometabolic, neurological, and psychiatric complications. ${ }^{[3,12-15]}$ The present review is intended to provide an overview of the spectrum of long-term complications, pathogenetic mechanisms, and anticipated protocols to prevent and manage these adverse chronic outcomes and disabilities. This is expected to help the physicians in providing follow-up primary and specialist care, and also the policymakers in planning and establishing mechanisms for providing efficient after-care or follow-up facility to COVID-19 patients.

\section{Overview}

Globally, till mid-September 2020, 29,444,198 confirmed cases of COVID-19, including 931,321 deaths, have been reported to the World Health Organization. ${ }^{[5]}$ With passing time, more information is becoming available in the world literature on the long-term complications of SARS-CoV-2 viral infection, ${ }^{[7,8,16]}$ particularly of patients that are suffering from severe form of the disease. ${ }^{[17]}$ Some of the reported complications include pulmonary dysfunction, exercise intolerance, cardiac compromise, psychological problems (posttraumatic stress disorders [PTSD], depression, and anxiety), and reduced quality of life, ${ }^{[13]}$ Possibly, it is the presence of coagulopathy and thrombotic disease in these patients that results in a variety of end-organ damage, persistent organ dysfunction, and compromised respiratory recovery. ${ }^{[18]}$ Ischemic stroke with occasional delayed presentation has also been reported in association with COVID-19. It can occur early in the course of the illness. ${ }^{[19]}$ There are isolated reports of severe neurological problems as well, for example, encephalitis, ${ }^{[20]}$ acute necrotizing encephalopathy and cerebrovascular diseases, ${ }^{[15,21]}$ cellular immune or antibody-mediated manifestations such as Guillain-Barré syndrome, ${ }^{[22,23]}$ Miller-Fisher syndrome, ${ }^{[24]}$ and Kawasaki-like multisystem inflammatory syndromes. ${ }^{[25]}$

\section{Pathophysiology of SARS-CoV-2 Infection}

Several hypotheses have been proposed to explain the mechanisms involved in the natural history of this disease from transmission of the infection, pathogenesis, and the complications of the COVID-19 disease. Most theories agree on the pathway that involves binding of SARS-CoV-2 to the angiotensin-converting enzyme-2 (ACE2) receptors, thereby invading the alveolar epithelial cells in lungs. This results in direct toxicity as well as enhanced immune response, leading to lung injury and associated morbidity and mortality. ${ }^{[26-30]}$ Similar ACE2-mediated action of SARS-CoV-2 can also affect the kidneys, heart, and intestines, thus leading to multiple organ dysfunction syndrome ${ }^{[31,32]}$ Another phenomenon that has been observed as a sudden worsening and complication of COVID-19 disease is the "cytokine release syndrome" or the "cytokine storm." This is caused by the triggering of immune system by the virus, resulting in a sudden release of various cytokines and related inflammatory mediators with damage to the tissues and vital organs including lungs, heart, and kidneys. ${ }^{[33,34]}$ The associated systemic inflammation can potentially cause cognitive decline and neurodegenerative disease, and this could be the cause of increased risk of neurodegenerative disorders in survivors. ${ }^{[35,36]}$ SARS-CoV-2-mediated prothrombotic state can cause elevated D-dimer, coagulopathy, and venous and arterial thromboembolism. ${ }^{[37,38]}$ This can lead to ischemic stroke ${ }^{[15]}$ and can also exaggerate the preexisting neurological disorders to worsen the cognitive impairments and motor deficits. ${ }^{[14]}$

\section{Risk Factors and the Vulnerable Population}

The SARS-CoV-2 viral infection in humans is classically characterized by fever, cough, diarrhea, and fatigue, with characteristic laboratory findings and characteristic lung abnormalities in the computed tomography scan. ${ }^{[8]}$ Studies have reported that COVID-19 survivors can have impaired diffusion capacity and restrictive ventilatory defect. The severity of the disease determines the extent of lung involvement. ${ }^{[39]}$ For primary prevention of long-term organ damage, it is important to identify the risk factors that make the patients vulnerable for long-term sequelae. Some of the predisposing conditions are presence of major organ involvement; ${ }^{[6,40-42]}$ dyspnea in acute phase requiring noninvasive or invasive mechanical ventilation, or extracorporeal membrane oxygenation; ${ }^{[6,8,41,43]}$ older age; comorbidities such as diabetes mellitus and HTN $;{ }^{[17,44,45]}$ and undernutrition. ${ }^{[17]}$ Longer duration of illness and poorer acute phase disease course are more likely to have long-term sequelae. Some of the long-term organ system damage and sequelae are discussed below.

\section{Respiratory system}

The SARS-CoV-2 viral infection predominantly involves the respiratory system. ${ }^{[46]}$ In fact, a spike in pneumonia cases was the first sign of this new coronavirus infection in China. Early reports from China reported acute respiratory distress syndrome as the most common as well as severe life-threatening complication of COVID-19 disease, with the severely damaged lung being full of leaked fluid and requiring mechanical ventilation. ${ }^{[47]}$ With passing of a few months, reports suggested that besides the acute illness, COVID-19 also has long-term respiratory sequelae and disability, and these appear to be similar to the infections by the SARS and MERS viruses. ${ }^{[48]}$ Long-term health issues of COVID-19 related to pulmonary disability are reduced aerobic capacity, ${ }^{[49]}$ persistent impaired pulmonary function, ${ }^{[12]}$ and impaired diffusion capacity. ${ }^{[50]}$ Chest roentgenogram of very ill COVID-19 patients showed a spectrum of pure and/or mixed ground-glass opacities to bilateral peripheral consolidations in their middle and lower lung zones that interfere with diffusion of oxygen in the pulmonary circulation. ${ }^{[51]}$ Almost one-fifth of the patients continue to experience cough, fatigue, and dyspnea several weeks after clinical recovery and discharge 
from hospital. ${ }^{[52]}$ The pathological changes in the lung include diffuse alveolar epithelial destruction, capillary damage, atrial septal fibrous proliferation, and pulmonary fibrosis that result in compromised lung function and pulmonary disability. ${ }^{[53]}$ The pulmonary function of such patients continues to be abnormal at the time of discharge as well as few weeks later. It remains to be seen whether these changes resolve and improve, or worsen with duration since acute illness. If parallels from the long-term effects of SARS and MERS infections are drawn, it is likely that some degree of pulmonary compromise and hence disability will remain. It is an important public health as well as socioeconomic consideration because it will require community-level resources for medical attention. It will adversely affect the activity level and working ability with slower recovery process with shortness of breath following severe infections, thereby affecting their work productivity and earnings.

\section{Cardiovascular system}

Recent findings suggest that in the acute phase of COVID-19 infection, the systemic inflammatory response is also accompanied by local vascular inflammation in the cardiovascular system, resulting in myocarditis and thromboembolic events. ${ }^{[54]}$ It is known that even after an episode of non-SARS pneumonia, the risk of cardiovascular disease rises almost 1.5 -fold by 1 year possibly because of persistent inflammatory mediators in the tissues. ${ }^{[12]}$ Similar risk has also been reported based on cardiovascular involvement in SARS and MERS. ${ }^{[12,55]}$ Studies from the USA and China have reported acute cardiac injuries and arrhythmias in hospitalized patients. In a Dutch study, up to one-third of the cases admitted in intensive care unit had deep-vein thrombosis, pulmonary embolism, or arterial clots, but none had disseminated intravascular coagulation (DIC). Another group of researchers postulated that SARS-CoV-2 may initiate COVID-19-associated coagulopathy that is manifested by change in protein levels, but not lead to DIC. ${ }^{[47]}$ The various cardiac enzymes (e.g., cardiac troponin 1, creatine kinase (CK) isoenzyme, and lactate dehydrogenase $[\mathrm{LDH}]$ ) that serve as markers of myocardial inflammation and damage are found elevated in acute SARS-CoV-2 infection, especially in the presence of severe disease. ${ }^{[53]}$ Long-term cardiovascular sequelae and morbidity of SARS-CoV-2 deserve continued systematic follow-up and documentation. This will help formulate appropriate rehabilitation support in the follow-up phase with in patients reporting with chest pain, palpitations, and other symptoms.

\section{Effect on liver}

Studies have suggested that seriously affected COVID-19 patients showed some degree of hepatic damage and hepatitis, though no clearly demarcated pathophysiology was found. It is still unclear whether this is because of the virus directly harming the hepatic tissue, or as a result of the systemic inflammation and thrombosis. Irrespective of the pathophysiological pathway, acute liver injury and liver failure are life-threatening complications of COVID-19 disease. ${ }^{[47]}$ It is also unclear whether this virus continues to harbor in the tissues after the clinical recovery, or if can cause long-term hepatic compromise as is the case with hepatitis $\mathrm{B}$ and $\mathrm{C}$ viruses.

\section{Kidney and urological effects}

It is increasingly recognized that many of the critical patients with severe form of COVID-19 disease develop acute renal injury and renal failure requiring emergency dialysis. Additionally, patients who have preexisting chronic renal disease (CKD) and associated comorbidities such as diabetes mellitus and HTN are at extreme risks and are prone to poor outcomes including death. It is still speculative whether the recovery from acute kidney injury due to COVID-19 is complete of has residual compromise in renal function, ${ }^{[47]}$ with potential worsening of preexisting renal disease and/or CKD, delay in seeking medical attention for urological problems, and residual sequelae with urological complications. ${ }^{[56]}$

\section{Metabolic and endocrinological effects}

Given a lack of prior clinical experience with the SARS-CoV-2 viral infection, it is prudent to revisit the long-term complications observed with the SARS infection 12 years ago and the MERS with reported newer onset of diabetes and HTN after COVID-19 recovery. This serves as a guide for monitoring in SARS-CoV-2 infection, especially in the postclinical recovery phase. Dyslipidemia and abnormal glucose metabolism were observed in the SARS survivors with a higher frequency among the healthy volunteers at 12 years after the acute disease. ${ }^{[12]}$ Triglyceride and very low-density lipoprotein levels were found elevated. ${ }^{[57]}$ Similarly, abnormal glucose metabolism in the form of hyperinsulinemia, insulin resistance, and hyperglycemia was observed with a higher frequency among the SARS survivors. ${ }^{[12,58]}$ These effects were possibly mediated by the elevated lysophosphatidylinositol, or even due to direct pancreatic islet damage from the virus and inflammation. The SARS-CoV-2 infection shares many of these metabolic injury pathways and similar long-standing complications are expected with passing time. It is also postulated that the use of steroids especially in high doses can potentially disturb the adrenocorticotropin hormone-cortisol axis, resulting in the symptoms of hypercortisolism such as lethargy, apathy, fatigue, dizziness, weakness, and orthostatic hypotension. ${ }^{[12,59,60]}$ Hypothyroidism is another long-term complication that was observed following recovery from acute SARS. The pathogenesis could have been direct thyroid damage, central hypothyroidism (due to hypophysitis), or subacute thyroiditis. Researchers anticipate similar trend in moderate-to-severe COVID-19 survivors, and propose suitable exercise, lifestyle modification, and better dietary habits in postrecovery phases. ${ }^{[12]}$

\section{Neuromusculoskeletal Complications}

Acute neurological events are being increasingly reported in many studies related to SARS-CoV-2 infection, ${ }^{[14]}$ including acute ischemic stroke that have a high morbidity and mortality ${ }^{[15,19,22,61-64]}$ Past experience with SARS infection suggested that, in spite of acute rehabilitation measures, neuromuscular abnormalities may persist, leading to difficulty 
in performing activities of daily living. ${ }^{[65]}$ Some studies have reported skeletal muscle damage and raised $\mathrm{CK}$ and $\mathrm{LDH}$ levels in patients who had clinical symptoms, suggestive of muscle involvement. ${ }^{[8,15]}$ The involvement of muscles in SARS-CoV-2 is attributed to elevated pro-inflammatory cytokines related immune damage to the skeletal muscle. However, this needs to be confirmed in future studies. ${ }^{[15]}$ There are also reports of "rhabdomyolysis" as an extremely rare complication, wherein there is breakdown of muscles and myoglobinuria that may lead to acute kidney injury with associated high mortality. ${ }^{[47]}$ Clinicians and researchers are continuing to study the residual neurological deficits at the time of discharge of the patients and the long-term impact such as cognitive decline, persistent neuromuscular deficit with inability to perform activities of daily living, weakness, reduced exercise capacity, etc. These effects could result from neuromuscular and various end-organ system damages, as well as due to prolonged immobilization during the acute phase. ${ }^{[12]}$ This emphasizes the need for physiotherapy during hospitalization and continued rehabilitative follow-up after discharge from the hospital. These disabilities can contribute to a major burden of compromised work capacity and its socioeconomic effects.

\section{Secondary Infection and Septic Shock Syndrome}

Secondary and opportunistic infections have been reported among hospitalized COVID-19 patients, with morbidity from uncommon but severe form of infections with Streptococcus and Staphylococcus. Chinese studies have also reported septic shock syndrome precipitated from generalized sepsis by triggering immunological pathways; unless treated on war footing, may be life-threatening. ${ }^{[47]}$

\section{Multisystem Inflammatory Syndrome in Children}

Hospitalized pediatric cases and adolescents with serious infections have been reported with "multisystem inflammatory syndrome in children" or "pediatric multisystem inflammatory syndrome" linked to SARS-CoV-2 with specific clinical features, namely pyrexia, pain abdomen, vomiting, diarrhea, rash, headache, and confusion. This clinical spectrum closely mimics toxic shock syndrome or Kawasaki disease following vascular inflammation in children. ${ }^{[47]}$

\section{Psychosomatic and Psychiatric Complications}

The past experience of similar viral infections particularly SARS, an increased incidence of various neuropsychiatric sequelae has been observed for many years after the acute illness. Similar pathophysiology has been postulated to be responsible for COVID-19-related behavioral and psychiatric complications in patients after acute illnesses such as depression, anxiety, PTSD, somatoform pain disorder, panic disorder ${ }^{[66]}$ reduced social functioning, ${ }^{[67]}$ and fear psychosis, ${ }^{[68]}$ as was seen in the SARS survivors. Studies have also reported an association between SARS and chronic fatigue syndrome, ${ }^{[69,70]}$ with the probable mechanism involving the ACE2 receptors that are the postulated portal of cellular entry for SARS-CoV-2 virus. ${ }^{[70]}$ There is an urgent need for holistic mitigation plan regarding well-designed interprofessional as well as multidisciplinary long-term rehabilitation framework to address the psychiatric dysfunction in SARS-CoV-2. ${ }^{[12]}$ Long-term complaints of individuals across age groups, gender, and ethnicity have also been reported in social media and professional communications namely extreme fatigue, low-grade fever, inability to concentrate, memory lapses, changes in mood, sleep difficulties, headache, needle pain in the upper and lower extremities, diarrhea and bouts of vomiting, loss of taste and smell, sore throat and dysphagia, and unclassified skin rashes. However, this information shall need more vigilance and investigations and may be useful for post-COVID-19 syndrome follow-ups.

\section{Conclusion}

The wide spectrum of long-term organ damage and complications as outlined in this review only further establishes the need for a concerted multidisciplinary effort for providing care for the same. Not only does the treating physicians need to anticipate these long-term complications and outcomes in SARS-CoV-2 survivors but also public health experts need to formulate a robust as well as holistic follow-up and rehabilitation protocols at hospital for providing postdischarge domiciliary care. This requires well-thought-out and evidence-based clinical practice guidelines with consensus of stakeholders. Standard operative office procedures based on data and knowledge sharing of anticipated long-term complications, warning signs, knowledge of risk factors and risk correlates, judicious use of supportive laboratory investigations, and identification of appropriate biochemical parameters are a must for the success of such an interprofessional rehabilitative model.

\section{Financial support and sponsorship}

Nil.

\section{Conflicts of interest}

There are no conflicts of interest.

\section{REFERENCES}

1. Zhu N, Zhang D, Wang W, Li X, Yang B, Song J, et al. A novel coronavirus from patients with pneumonia in China, 2019. N Engl J Med 2020;382:727-33.

2. Gorbalenya AE, Baker SC, Baric RS, de Groot RJ, Drosten C, Gulyaeva AA, et al. The species severe acute respiratory syndrome-related coronavirus: Classifying 2019-nCoV and naming it SARS-CoV-2. Nat Microbiol 2020;5:536-44.

3. Peeri NC, Shrestha N, Rahman MS, Zaki R, Tan Z, Bibi S, et al The SARS, MERS and novel coronavirus (COVID-19) epidemics, the newest and biggest global health threats: What lessons have we learned? Int J Epidemiol 2020;49:717-26.

4. World Health Organization. WHO Director-General's Opening Remarks at the Media Briefing on COVID-19. World Health Organization; 11 March, 2020. Available from: https://www. who.int/dg/speeches/detail/who-director-general-s-openingremarks-at-the-media-briefing-on-covid-19---11-march-2020. [Last accessed on 2020 Sep 17]. 
5. World Health Organization. Coronavirus Disease (COVID-19). World Health Organization; 2020. Available from: https://www.who.int/ emergencies/diseases/novel-coronavirus-2019. [Last accessed on 2020 Sep 17].

6. Yang X, Yu Y, Xu J, Shu H, Xia J, Liu H, et al. Clinical course and outcomes of critically ill patients with SARS-coV-2 pneumonia in Wuhan, China: A single-centered, retrospective, observational study. Lancet Respir Med 2020;8:475-81.

7. Grasselli G, Zangrillo A, Zanella A, Antonelli M, Cabrini L, Castelli A, et al. Baseline characteristics and outcomes of 1591 patients infected with SARS-coV-2 admitted to ICUs of the Lombardy Region, Italy. JAMA 2020;323:1574-81

8. Guan WJ, Ni ZY, Hu Y, Liang WH, Ou CQ, He JX, et al. Clinical characteristics of coronavirus disease 2019 in China. N Engl J Med 2020;382:1708-20.

9. Verity R, Okell LC, Dorigatti I, Winskill P, Whittaker C, Imai N, et al. Estimates of the severity of coronavirus disease 2019: A model-based analysis. Lancet Infect Dis 2020;20:669-77.

10. Chan KS, Zheng JP, Mok YW, Li YM, Liu YN, Chu CM, et al. SARS: Prognosis, outcome and sequelae. Respirology 2003;8 Suppl: S36-40.

11. Petrie JG, Cheng C, Malosh RE, VanWormer JJ, Flannery B, Zimmerman RK, et al. Illness Severity and Work Productivity Loss Among Working Adults With Medically Attended Acute Respiratory Illnesses: US Influenza Vaccine Effectiveness Network 2012-2013. Clin Infect Dis. 2016 Feb 15;62(4):448-455. doi: 10.1093/cid/civ952. Epub 2015 Nov 12. PMID: 26565004 ; PMCID: PMC4725387.

12. Dasgupta A, Kalhan A, Kalra S. Long term complications and rehabilitation of COVID-19 patients. J Pak Med Assoc 2020;70 Suppl 3:S131-5.

13. Ahmed H, Patel K, Greenwood DC, Halpin S, Lewthwaite P, Salawu A, et al. Long-term clinical outcomes in survivors of severe acute respiratory syndrome and Middle East respiratory syndrome coronavirus outbreaks after hospitalisation or ICU admission: A systematic review and meta-analysis. J Rehabil Med. 2020 May 31;52(5):jrm00063. doi: 10.2340/16501977-2694. PMID: 32449782.

14. Helms J, Kremer S, Merdji H, Clere-Jehl R, Schenck M, Kummerlen C, et al. Neurologic features in severe SARS-CoV-2 infection. N Engl J Med 2020;382:2268-70.

15. Mao L, Jin $\mathrm{H}$, Wang $\mathrm{M}, \mathrm{Hu} \mathrm{Y}$, Chen $\mathrm{S}$, He Q, et al. Neurologic manifestations of hospitalized patients with coronavirus disease 2019 in Wuhan, China. JAMA Neurol 2020;77:683-90.

16. Heneka MT, Golenbock D, Latz E, Morgan D, Brown R. Immediate and long-term consequences of COVID-19 infections for the development of neurological disease. Alzheimers Res Ther 2020;12:69.

17. Tenforde MW, Kim SS, Lindsell CJ, et al. Symptom Duration and Risk Factors for Delayed Return to Usual Health Among Outpatients with COVID-19 in a Multistate Health Care Systems Network United States, March-June 2020. MMWR Morb Mortal Wkly Rep 2020;69:993-8.

18. Tang N, Bai H, Chen X, Gong J, Li D, Sun Z, et al. Anticoagulant treatment is associated with decreased mortality in severe coronavirus disease 2019 patients with coagulopathy. J Thromb Haemost 2020;18:1094-9.

19. Beyrouti R, Adams ME, Benjamin L, Cohen H, Farmer SF, Goh YY, et al. Characteristics of ischaemic stroke associated with COVID-19. J Neurol Neurosurg Psychiatry 2020;91:889-91.

20. Moriguchi T, Harii N, Goto J, Harada D, Sugawara H, Takamino J, et al. Afirst case of meningitis/encephalitis associated with SARS-Coronavirus-2. International journal of infectious diseases: IJID 2020;94:55-8.

21. Ellul MA, Benjamin L, Singh B, Lant S, Michael BD, Easton A, et al. Neurological associations of COVID-19. Lancet Neurol 2020;19:767-83.

22. Giannis D, Ziogas IA, Gianni P. Coagulation disorders in coronavirus infected patients: COVID-19, SARS-coV-1, MERS-coV and lessons from the past. J Clin Virol 2020;127:104362.

23. Toscano G, Palmerini F, Ravaglia S, Ruiz L, Invernizzi P, Cuzzoni MG, et al. Guillain-Barré syndrome associated with SARS-CoV-2. N Englv J Med 2020;382:2574-6.

24. Gutiérrez-Ortiz C, Méndez-Guerrero A, Rodrigo-Rey S, San Pedro-Murillo E, Bermejo-Guerrero L, Gordo-Mañas R, et al. Miller Fisher syndrome and polyneuritis cranialis in COVID-19. Neurology. 2020 Aug 4;95(5):e601-e605. doi: 10.1212/WNL.0000000000009619.
Epub 2020 Apr 17. PMID: 32303650.

25. Jones VG, Mills M, Suarez D, Hogan CA, Yeh D, Segal JB, et al. COVID-19 and Kawasaki disease: Novel virus and novel case. Hosp Pediatr 2020;10:537-40.

26. Xu X, Chen P, Wang J, Feng J, Zhou H, Li X, et al. Evolution of the novel coronavirus from the ongoing Wuhan outbreak and modeling of its spike protein for risk of human transmission. Sci China Life Sci 2020;63:457-60.

27. Cheng ZJ, Shan J. 2019 Novel coronavirus: Where we are and what we know. Infection 2020;48:155-63.

28. Jiang S, Du L, Shi Z. An emerging coronavirus causing pneumonia outbreak in Wuhan, China: Calling for developing therapeutic and prophylactic strategies. Emerg Microbes Infect 2020;9:275-7.

29. Kuba K, Imai Y, Rao S, Gao H, Guo F, Guan B, et al. A crucial role of angiotensin converting enzyme 2 (ACE2) in SARS coronavirus-induced lung injury. Nat Med 2005;11:875-9.

30. Ren LL, Wang YM, Wu ZQ, Xiang ZC, Guo L, Xu T, et al. Identification of a novel coronavirus causing severe pneumonia in human: A descriptive study. Chin Med J (Engl) 2020;133:1015-24.

31. Chai X, Hu L, Zhang Y, Han W, Lu Z, Ke A, et al. Specific ACE2 expression in cholangiocytes may cause liver damage after 2019-nCoV infection. bioRxiv (pre-print). 2020.02.03.931766; doi: https://doi. org/10.1101/2020.02.03.931766.

32. Zhao Y, Zhao Z, Wang Y, Zhou Y, Ma Y, Zuo W. Single-Cell RNA Expression Profiling of ACE2, the Receptor of SARS-CoV-2. Am J Respir Crit Care Med 2020;202:756-9. doi: 10.1164/rccm.2020010179LE. PMID: 32663409; PMCID: PMC7462411.

33. Chen G, Wu D, Guo W, Cao Y, Huang D, Wang H, et al. Clinical and immunological features of severe and moderate coronavirus disease 2019. J Clin Invest 2020;130:2620-9.

34. Mehta P, McAuley DF, Brown M, Sanchez E, Tattersall RS, Manson JJ, et al. COVID-19: Consider cytokine storm syndromes and immunosuppression. Lancet 2020;395:1033-4.

35. Iwashyna TJ, Ely EW, Smith DM, Langa KM. Long-term cognitive impairment and functional disability among survivors of severe sepsis. JAMA 2010;304:1787-94.

36. Widmann CN, Heneka MT. Long-term cerebral consequences of sepsis. Lancet Neurol 2014;13:630-6.

37. Tang N, Li D, Wang X, Sun Z. Abnormal coagulation parameters are associated with poor prognosis in patients with novel coronavirus pneumonia. J Thromb Haemost 2020;18:844-7.

38. Chen N, Zhou M, Dong X, Qu J, Gong F, Han Y, et al. Epidemiological and clinical characteristics of 99 cases of 2019 novel coronavirus pneumonia in Wuhan, China: A descriptive study. Lancet (London, England). 2020;395:507-13.

39. Mo X, Jian W, Su Z, Chen M, Peng H, Peng P, et al. Abnormal pulmonary function in COVID-19 patients at time of hospital discharge. Eur Respir J. 2020 Jun 18;55(6):2001217. doi: 10.1183/13993003.01217-2020. PMID: 32381497; PMCID: PMC7236826.

40. Fan Z, Chen L, Li J, Cheng X, Yang J, Tian C, et al. Clinical Features of COVID-19-Related Liver Functional Abnormality. Clin Gastroenterol Hepatol 2020;18:1561-6. doi: 10.1016/j.cgh.2020.04.002. Epub 2020 Apr 10. PMID: 32283325; PMCID: PMC7194865.

41. Li X, Wang L, Yan S, Yang F, Xiang L, Zhu J, et al. Clinical characteristics of 25 death cases with COVID-19: A retrospective review of medical records in a single medical center, Wuhan, China. Int $\mathrm{J}$ Infect Dis 2020;94:128-32.

42. Ma L, Xie W, Li D, et al. Effect of SARS-CoV-2 infection upon male gonadal function: A single center-based study. medRxiv; 2020. DOI: 10.1101/2020.03.21.20037267.

43. Wang D, Hu B, Hu C, Zhu F, Liu X, Zhang J, et al. Clinical characteristics of 138 hospitalized patients with 2019 novel coronavirus-infected pneumonia in Wuhan, China. JAMA 2020;323:1061-9.

44. Huang C, Wang Y, Li X, Ren L, Zhao J, Hu Y, et al. Clinical features of patients infected with 2019 novel coronavirus in Wuhan, China. Lancet (London, England) 2020;395:497-506.

45. Zhou F, Yu T, Du R, Fan G, Liu Y, Liu Z, et al. Clinical course and risk factors for mortality of adult inpatients with COVID-19 in Wuhan, China: A retrospective cohort study. Lancet 2020;395:1054-62.

46. Hosseiny M, Kooraki S, Gholamrezanezhad A, Reddy S, Myers L. Radiology perspective of coronavirus disease 2019 (COVID-19): 
Lessons from severe acute respiratory syndrome and middle east respiratory syndrome. AJR Am J Roentgenol 2020;214:1078-82.

47. Complications of Coronavirus (COVID-19); 2020. Available from: https://www.webmd.com/lung/coronavirus-complications. [Last accessed on 2020 Sep 17].

48. Wu X, Dong D, Ma D. Thin-section computed tomography manifestations during convalescence and long-term follow-up of patients with severe acute respiratory syndrome (SARS). Med Sci Monit 2016;22:2793-9.

49. Ong $\mathrm{KC}, \mathrm{Ng} \mathrm{AW}$, Lee LS, Kaw G, Kwek SK, Leow MK, et al. Pulmonary function and exercise capacity in survivors of severe acute respiratory syndrome. Eur Respir J 2004;24:436-42.

50. Zhang P, Li J, Liu H, Han N, Ju J, Kou Y, et al. Long-term bone and lung consequences associated with hospital-acquired severe acute respiratory syndrome: A 15-year follow-up from a prospective cohort study. Bone Res 2020;8:8

51. Durrani M, Haq IU, Kalsoom U, Yousaf A. Chest X-rays findings in COVID 19 patients at a university teaching hospital A descriptive study. Pak J Med Sci 2020;36:S22-6.

52. Carfi A, Bernabei R, Landi F; Gemelli Against COVID-19 Post-Acute Care Study Group. Persistent symptoms in patients after acute COVID-19. JAMA 2020;324:603-5.

53. Li J. Rehabilitation management of patients with COVID-19: Lessons learned from the first experience in China. Eur J Phys Rehabil Med 2020;56:335-8.

54. Madjid M, Safavi-Naeini P, Solomon SD, Vardeny O. Potential effects of coronaviruses on the cardiovascular system: A review. JAMA Cardiol 2020;5:831-40.

55. Corrales-Medina VF, Alvarez KN, Weissfeld LA, Angus DC, Chirinos JA, Chang CC, et al. Association between hospitalization for pneumonia and subsequent risk of cardiovascular disease. JAMA 2015;313:264-74.

56. Morlacco A, Motterle G, Zattoni F. The multifaceted long-term effects of the COVID-19 pandemic on urology. Nat Rev Urol 2020;17:365-7.

57. Wu Q, Zhou L, Sun X, Yan Z, Hu C, Wu J, et al. Altered lipid metabolism in recovered SARS patients twelve years after infection. Sci Rep 2017;7:9110.

58. Yang JK, Lin SS, Ji XJ, Guo LM. Binding of SARS coronavirus to its receptor damages islets and causes acute diabetes. Acta Diabetol
2010;47:193-9.

59. Chrousos GP, Kaltsas G. Post-SARS sickness syndrome manifestations and endocrinopathy: How, why, and so what? Clin Endocrinol (Oxf) 2005;63:363-5.

60. Leow MK, Kwek DS, Ng AW, Ong KC, Kaw GJ, Lee LS, et al. Hypocortisolism in survivors of severe acute respiratory syndrome (SARS). Clin Endocrinol (Oxf) 2005;63:197-202.

61. Boehme AK, Ranawat P, Luna J, Kamel H, Elkind MS. Risk of acute stroke after hospitalization for sepsis: A case-crossover study. Stroke 2017;48:574-80.

62. González-Pinto T, Luna-Rodríguez A, Moreno-Estébanez A, Agirre-Beitia G, Rodríguez-Antigüedad A, Ruiz-Lopez $\mathrm{M}$, et al. Emergency room neurology in times of COVID-19: Malignant ischaemic stroke and SARS-coV-2 infection. Eur J Neurol 2020;27:e35-6.

63. Zhang Y, Xiao M, Zhang S, Xia P, Cao W, Jiang W, et al. Coagulopathy and antiphospholipid antibodies in patients with covid-19. N Engl J Med 2020;382:e38.

64. Oxley TJ, Mocco J, Majidi S, Kellner CP, Shoirah H, Singh IP, et al. Large-vessel stroke as a presenting feature of covid-19 in the young. N Engl J Med 2020;382:e60.

65. Law RK, Lee EW, Poon PY, Lau TC, Kwok KM, Chan AC, et al. The functional capacity of healthcare workers with history of severe acute respiratory distress syndrome (SARS) complicated with avascular necrosis - case report. Work 2008;30:17-26.

66. Wing YK, Leung CM. Mental health impact of severe acute respiratory syndrome: A prospective study. Hong Kong Med J 2012;18 Suppl 3:24-7.

67. Tansey CM, Louie M, Loeb M, Gold WL, Muller MP, de Jager J, et al. One-year outcomes and health care utilization in survivors of severe acute respiratory syndrome. Arch Intern Med 2007;167:1312-20.

68. Bener A, Al-Khal A. Knowledge, attitude and practice towards SARS. J R Soc Promot Health 2004;124:167-70.

69. Lam MH, Wing YK, Yu MW, Leung CM, Ma RC, Kong AP, et al. Mental morbidities and chronic fatigue in severe acute respiratory syndrome survivors: Long-term follow-up. Arch Intern Med 2009;169:2142-7.

70. Vladutiu GD, Natelson BH. Association of medically unexplained fatigue with ACE insertion/deletion polymorphism in gulf war veterans. Muscle Nerve 2004;30:38-43. 